\title{
Intravenous urography and childhood trauma
}

\author{
N. M. OKORIE \\ M.D. \\ A. E. MACKINNON* \\ M.B., B.S., F.R.C.S. \\ Department of Paediatric Surgery, University of Nigeria Teaching Hospital, P.M.B. 1129, Enugu, Nigeria and \\ *Children's Hospital, Western Bank, Sheffield S10 2TH
}

\section{Summary}

Results of intravenous urography (IVU) in 33 patients suspected of suffering from renal trauma were reviewed. It was concluded that when haematuria is only detected microscopically and clears within $24 \mathrm{hr}$ then an IVU is not necessary, in the absence of other evidence of significant urinary tract injury.

\section{Introduction}

Emergency intravenous urography is considered an essential examination in the evaluation of any patient suspected of having suffered renal trauma (Editorial, 1979). This practice is derived from clinical experience in adults.

The purpose of this paper is to evaluate the need for emergency urography in children, particularly those suffering from only minor renal trauma. It is based on a retrospective review of the cases of renal trauma admitted to the Paediatric Surgical Unit of the Children's Hospital, Sheffield, during the period 1969-1979. The patients were suspected to have suffered renal trauma on the basis of the history, symptoms, signs and site of their injuries.

\section{Clinical material and findings}

The records of all the patients suffering from renal trauma who were admitted to our Unit between 1969 and 1979 were reviewed. There was a total of 39 patients, of whom 29 were boys. Their ages ranged from 4 to 14 years. Injury to the right kidney was suspected in 22 cases, and to the left kidney in 17. Haematuria was present in 36 patients (92.3\%) and was classified as follows:

1. Gross: Blood frankly visible.

2. Moderate: Turbid or cloudy urine requiring microscopy or chemical testing to confirm presence of blood, or microscopic haematuria persisting for more than 24 hours.

Requests for reprints: Mr A. E. MacKinnon
3. Mild: Blood only detected by microscopy or chemical testing and clearing within 24 hours of injury.

Gross haematuria occurred in 22 cases $(56 \cdot 4 \%)$. Moderate haematuria in one case and mild haematuria in 13 cases $(33 \cdot 3 \%)$.

TABLE 1. Results of urography in 33 cases of suspected renal trauma

\begin{tabular}{lccc}
\hline Haematuria & Number of patients & Normal & Abnormal \\
\hline Gross & 22 & 5 & 17 \\
Moderate & 1 & 1 & - \\
Mild & 7 & 7 & - \\
None & 3 & 3 & - \\
\hline
\end{tabular}

Intravenous urography (IVU) was performed in 30 out of 36 patients who presented with haematuria, and in 3 patients with no haematuria (Table 1). In this latter group no abnormality was found. Urography was not performed in 6 cases who were found to have only mild haematuria. All 7 patients with mild haematuria who underwent urography had no detectable abnormality. Likewise, the urogram of the patient with moderate haematuria was normal. Out of 22 patients with gross haematuria, the $\mathrm{X}$-rays revealed renal pathology in 17 cases (Table 2.).

TABLE 2. Details of abnormal IVU findings in 17 out of 22 patients with gross haematuria

\begin{tabular}{ll}
\hline Renal rupture & 7 \\
Renal contusion & 8 \\
Duplex ureters & 3 \\
Polycystic kidneys & 1 \\
\hline
\end{tabular}

Extravasation of urine occurred in 7 children, indicating rupture of the renal parenchyma or pelvis. Of these 7 cases, 6 were treated conservatively and follow-up studies indicated return to normal function, including one child who had a transient upper 
ureteric obstruction. The seventh child was found at the initial X-ray to have a non-functioning upper pole of the right kidney and later underwent a heminephrectomy. Renal contusion manifested by poor concentration of contrast material or delayed excretion was seen in 8 cases, but in each patient subsequent urography revealed that function had returned to normal. Some of these patients may also have had a minor renal rupture, but no extravasation of contrast was clearly demonstrated.

Incidental findings not related to the trauma were seen in 4 children. Ureteric duplication was found in 3 children. In one there was bilateral duplication with rupture of the upper pole of the right kidney. One child suffered rupture of the contralateral kidney, and in the third child there was no radiological evidence of renal damage even though the injury was on the same side as the duplication. Previously unrecognized polycystic renal disease was found in one child, though there was no evidence of renal damage.

\section{Discussion}

Intravenous urography has been advocated in every case of renal tract trauma (Mitchell, 1971; Schärli, 1977; Bright et al., 1978). Other authors extend their indications for urography to all cases of abdominal injury, regardless of the presence or absence of haematuria (Griffen et al., 1978). However, McDonald et al. (1976) observed that excretion urography rarely influences the management of the patient. Moreover, the estimated radiation dose to the gonads during intravenous urography ranges from 60 mrad. for boys to $164 \mathrm{mrad}$. for girls (Wall et al., 1980) and it must be assumed that any radiation, no matter what form or amount, represents some risk to individuals and society (Godfrey, 1981).

The present review supports the opinion that an urgent urogram is needed in any child who presents with gross haematuria of traumatic origin. Also, urography is essential when there is clinical suspicion of significant trauma, even in the absence of haematuria. We consider that patients with moderate haematuria, including those children in whom microscopic haematuria does not resolve within $24 \mathrm{hr}$, should have urography performed, though not necessarily as an emergency.

In the present series, 7 of the 13 children with mild haematuria underwent radiological examination, which was normal in each case. A further 6 patients did not undergo urography, but their haematuria cleared within $24 \mathrm{hr}$ of injury, and all were followed up for at least 4 weeks. They remained symptom-free and the haematuria did not recur.

We conclude that intravenous urography is not necessary in children who, following trauma, are found to have transient microscopic haematuria with no other signs or symptoms related to the renal tract.

\section{Acknowledgment}

The authors wish to thank Dr G. M. Steiner for his advice during the preparation of this paper.

\section{References}

Bright, T.C., White, K. \& Peters, P.C. (1978) Significance of haematuria after trauma. Journal of Urology, 120, 455.

EDITORIAL (1979) British Medical Journal, 1, 841.

GODFREY, B. (1981) Living with radiation. Health Trends, 18, 72. Griffen Jr, W.O., Belin, R.P., ERnSt, C.B., SaChatello, C.R Daugherty, M.E., Mulcahy, J.J., Chuang, V.A. \& MaUlō K.I. (1978) Intravenous pyelography in abdominal traum? Journal of Trauma, 18, 387.

McDonald, E.J., Korobkin, M., Jacobs, R.P. \& Miragi, H. (1976) The role of emergency excretory urography in evaluation of blunt, abdominal trauma. American Journal of Roentgenology, 126, 739.

MitCHELL, J.P. (1971) Trauma to the urinary tract. British Medical Journal, 2, 567.

SCHÄRLI, A.F. (1977) Injuries to the kidney. In: Surgical Paediatric Urology. (Ed by Eckstein, H.B., Hohenfellner, R. \& Williams, D.I.), p. 478. Saunders, Philadelphia.

WALl, B.F., Fisher, E.S., Shrimpton, P.C. \& RAE, S. (1980) Current levels of gonadal irradiation from a selection of routine diagnostic $X$-ray examinations in Great Britain. pp. 42, 43. National Radiological Protection Board-R105. 